\title{
A Teoria Garantista de Luigi Ferrajoli e a política de drogas do
}

\section{The Garantista Theory of Luigi Ferrajoli and the drug policy of Brazil}

Henrique Sartori de Almeida Prado ${ }^{1}$ João Felipe Ferreira de Souza Nogueira ${ }^{2}$

\section{RESUMO:}

O presente artigo tem por objetivo analisar os princípios da Teoria Garantista aplicada à lei de drogas do Brasil. Para o estudo utilizamos o método bibliográfico para conceituar os princípios da Teoria Garantista. A Teoria Garantista de Luigi Ferrajoli foi desenvolvida na intenção de preservar direitos e garantias de cidadãos condenados pelo sistema penal e visa tutelar as liberdades do indivíduo frente às variadas formas do exercício arbitrário de poder do Estado. É em busca da defesa do Estado de Direito e do ordenamento democrático que nasce o garantismo jurídico. A teoria do garantismo consiste na proposição de uma nova teoria do direito, onde são acrescidos alguns novos entendimentos sobre o respeito e a prevalência da Constituição Federal e dos princípios constitucionais na aplicação de penalidades, como os princípios da legalidade, lesividade, materialidade e proporcionalidade. A Constituição Federal brasileira prevê um amplo leque de direitos e garantias aos cidadãos, como o direito à liberdade, à inviolabilidade da vida privada, à autonomia de escolhas e esses direitos também se estendem aos usuários de drogas. No caso da política de drogas do Brasil, a teoria garantista proporciona analisar a arbitrariedade do Estado na aplicação de penalidades inconstitucionais e desproporcionais ao usuário e consumidor de drogas que, ao consumir determinada droga, pode ser processado e punido pelo sistema penal, mesmo que não coloque em risco bens jurídicos tuteláveis.

\section{PALAVRAS-CHAVE:}

Teoria Garantista. Política de Drogas. Direitos Constitucionais.

\footnotetext{
${ }^{1}$ Chanceler do grupo Estácio. Doutor em Ciência Política pelo Instituto de Estudo Sociais e Políticos (IESP/UERJ). Mestre em Direito, Relações Internacionais e Desenvolvimento pela Pontifícia Universidade Católica de Goiás (PUC-Goiás). Especialista em Relações Internacionais pela Universidade de Brasília (IREL-UNB) e Bacharel em Direito pela Universidade para o Desenvolvimento do Estado e da Região do Pantanal. Foi Ministro da Educação Substituto (MEC), Secretário-Executivo do Ministério da Educação (SE/MEC), Secretário Nacional de Regulação e Supervisão da Educação Superior do Ministério da Educação (SERES/MEC) e Secretário-Executivo do Conselho Nacional de Educação (CNE-MEC).

2 Mestre em Fronteiras e Direitos Humanos pela Faculdade de Direito e Relações Internacionais - FADIR, da Universidade Federal da Grande Dourados - UFGD. Pesquisador da Política Criminal de Drogas no Brasil e nos países do Mercosul em relação às violações direitos fundamentais decorrentes da guerra contra as drogas. Possui graduação em Direito pelo Centro Universitário da Grande Dourados - UNIGRAN (2015).
} 


\begin{abstract}
:
This article aims to analyze the principles of the Guarantor Theory applied to the drug law of Brazil. For the study we used the bibliographical method to conceptualize the principles of the theory of guarantor. The Garantista theory of Luigi Ferrajoli was developed with the intention of preserving the rights and guarantees of citizens condemned by the penal system and aims to protect the freedoms of the individual in face of the varied forms of the arbitrary exercise of state power. It is in search of the defense of the Rule of Law and of the democratic order that the juridical guarantee is born. The theory of guaranty consists in the proposition of a new theory of law, which adds some new understandings about the respect and the prevalence of the Federal Constitution and the constitutional principles in the application of penalties, such as the principles of legality, lesivity, materiality and proportionality. The Brazilian Federal Constitution provides a wide range of rights and guarantees to citizens, such as the right to freedom, inviolability of private life, autonomy of choices and these rights also extend to drug users. In the case of Brazilian drug policy, the Guarantor theory provides an analysis of the arbitrariness of the State in the application of unconstitutional and disproportionate penalties to the user and consumer of drugs that, when consuming a particular drug, can be prosecuted and punished by the penal system, jeopardize legal interests.
\end{abstract}

\title{
KEYWORDS:
}

Garantista theory. Drug Policy. Constitutional Rights.

\section{INTRODUÇÃO}

O Brasil, seguindo o modelo americano, adotou uma política antidrogas baseada na prevenção e repressão ao consumo de drogas ilícitas. As substâncias consideradas ilícitas são classificadas pela Agência Nacional de Vigilância Sanitária - ANVISA. Segundo a Organização Mundial da Saúde - OMS (1993, 69-82), “droga é toda substância natural ou sintética que introduzida no organismo vivo, pode modificar uma ou mais de suas funções". Portanto, em termos gerais, drogas podem ser classificadas como qualquer substância química, natural ou sintética, capaz de modificar um sistema biológico.

Em busca da repressão ao consumo e comércio ilegal de Drogas foi somente em 1940 que se observou o surgimento de política proibicionista sistematizada no Brasil. Desde a década de 40 até os dias atuais as legislações antidrogas do país ainda mantém seu discurso de repressão ao tráfico e prevenção ao consumo de drogas. Contudo, por vários anos de repressão ao 
consumo e tráfico de drogas, o Estado não atingiu seu objetivo de eliminar ou reduzir o consumo e o tráfico de drogas.

Em decorrência da ineficácia das legislações anteriores e da falha da política de repressão às drogas, entra em vigor a Lei n. 11.343/2006, que nivela a importância do tratamento diferenciado entre usuários e traficantes. Além disso, a lei 11.343/2006 trata da efetivação de uma nova política nacional sobre drogas através do abrandamento e adequação das penas cominadas à conduta de uso, de forma a impor sanção que vise reeducar e ressocializar o usuário.

A lei de drogas também propunha uma política de redução de danos que projetava ações de atenção aos usuários e dependentes, juntamente com seus familiares e busca a melhoria da qualidade de vida e à redução de riscos e danos associados ao uso ou dependência, bem como a (re)inserção ou (re)integração dos usuários na sociedade. Porém, o atual governo, caminhando contrário aos países que trabalham dentro da redução dos danos associados ao uso e abuso de drogas, elaborou o decreto 9.761 de 11 de abril de 2019, que prevê a manutenção da abstinência, como forma de melhoria das condições de saúde.

O Conselho Federal de Psicologia - CFP (2019), explica que a medida é muito nociva à população, pois a lógica da redução de danos é o princípio básico de respeito ao sujeito, a sua condição e sua autonomia da vida privada. Para o órgão, a política de redução de danos é uma política de resistência e busca preservar os direitos fundamentais e humanos do cidadão envolvido com drogas. E ainda, enquanto o mundo inteiro caminha para a mudança, no tocante às políticas de drogas e ao respeito aos direitos fundamentais, o Brasil volta ao modelo anterior e aumenta a repressão e a violação aos direitos.

Apesar de estabelecer formalmente a impossibilidade de aplicação de pena carcerária aos sujeitos envolvidos com drogas, as medidas terapêuticas, adotadas pela justiça terapêutica, conservam mecanismos penais de controle, com similar efeito moralizador e normalizador e obstruem a implementação de políticas públicas saudáveis. A justiça terapêutica é definida como medidas sociais e de tratamento às pessoas que praticam crimes envolvidos com o consumo de drogas. Nesse caminho, conclui Rolim que: 


\begin{abstract}
'vegetação vingadora' das quadrilhas de traficantes, dos massacres nas favelas, da superlotação prisional, da ausência de alternativas para o tratamento dos dependentes e da corrupção que atinge a polícia e se espalha por todas as instâncias de poder. Por esses e outros efeitos, nunca foi tão evidente a necessidade de se mudar a política de drogas em nosso país (ROLIM, 2009. p.175).
\end{abstract}

Segundo o autor, projetos de redução de danos desenvolvidos sob a visão de uma política proibicionista são enterradas pela lógica moralista, o que de certa forma, favorecem a atuação do mercado clandestino de drogas. Tais princípios redutores já foram rechaçados pelo Estado e a busca violenta da repressão ao tráfico e consumo de drogas, continua se efetivando com a violação de direitos e garantias constitucionais, principalmente do usuário de drogas.

Ferrajoli (1991) ensina que as normas proibitivas do uso pessoal de determinadas substâncias enunciam preceitos morais, representando a confusão pré-moderna dos séculos passados, onde as normas penais ocupam funções propagandísticas ou pedagógicas. Na lei 11.343/06 foram criados dois estatutos autônomos com respostas punitivas de natureza distinta, todavia o sistema repressivo foi mantido: alta repressão ao traficante de drogas, com imposição de severo regime de punibilidade; e patologização do usuário e do dependente com aplicação de penas e medidas alternativas (CARVALHO, 1996).

A lei 11.343/2006 inaugurou uma nova política nacional sobre drogas, oferecendo um tratamento mais humanitário aos usuários e dependentes de droga, tendo em vista que, apesar de ainda ser uma conduta típica, o uso de drogas, não é mais punido com penas corporais, ou seja, supostamente, não há mais prisão pelo uso de drogas. As penas cominadas tem previsão constitucional, inclusive e estão descritas no artigo 28 da citada lei.

Art. 28. Quem adquirir, guardar, tiver em depósito, transportar ou trouxer consigo, para consumo pessoal, drogas sem autorização ou em desacordo com determinação legal ou regulamentar será submetido às seguintes penas: I - advertência sobre os efeitos das drogas; II - prestação de serviços à comunidade; III - medida educativa de comparecimento a programa ou curso educativo. $\S 1^{\circ}$. Às mesmas medidas submetese quem, para seu consumo pessoal, semeia, cultiva ou colhe plantas destinadas à preparação de pequena quantidade de substância ou produto capaz de causar dependência física ou psíquica.

Assim, mesmo não oferecendo perigo de dano a bens jurídicos relevantes ou à liberdade de terceiros, o usuário de drogas ilícitas recebe as penalizações desproporcionais ditadas pela lei, que de acordo com a Teoria Garantista de Ferrajoli, é uma penalidade inconstitucional. 
Nesse sentido, o presente artigo tem como escopo demonstrar a inconstitucionalidade da aplicação de penalidades ao usuário de drogas que não coloca em risco a liberdade de terceiros ou bens jurídicos alheios, tendo em vista que a conduta do consumo de drogas, na maioria dos casos, não é potencialmente ofensiva para ser penalizada.

A pergunta problema utilizada como padrão para a delimitação do objeto da pesquisa em questão é a seguinte: É constitucional a aplicação de penalidades ao usuário de drogas que não coloca em risco bens jurídicos relevantemente tuteláveis pelo direito? Ao longo do trabalho relataram-se as penalidades aplicadas pela lei de drogas ao usuário e os princípios constitucionais e penais adotados pela Teoria Garantista na busca da efetivação dos direitos e garantias fundamentais dos cidadãos envolvidos com drogas, uma vez que a penalidade aplicada não é proporcional à conduta dos consumidores.

No presente trabalho foi utilizado o método dedutivo, em função da possibilidade de se partir de um enunciado maior, analisar e estabelecer relações com outro enunciado a fim de se chegar a uma conclusão. Trata-se de pesquisa bibliográfica e documental com a realização de uma análise de legislações, tratados, livros e publicações periódicas que tratam sobre a temática da política de drogas e a violação de direitos.

\section{A POLÍTICA DE DROGAS DO BRASIL}

O uso de drogas é um tema rotineiramente abordado e alvo de polêmicas principalmente quando se trata do assunto da descriminalização do consumo. Isto porque, em certas condições, como no caso da lei de drogas, é passível e gradativa a elevação do consumidor a traficante e delinquente, tendo em vista que a lei de drogas brasileira, não define especificamente quem é o usuário e quem é o traficante e cabe ao Estado, por meio das forças policiais e do poder judiciário qualificar cada caso como tráfico de drogas ou porte de drogas para consumo.

Gilberta Acselrad (2005) ensina que no contexto atual sobre drogas, a construção de um discurso próprio implica em incorporar argumentos múltiplos e encadeados: químicos, 
neurobiológicos, médicos, psicológicos, éticos, sociológicos, históricos, culturais, jurídicos, econômicos, políticos. Segundo a autora, o consumo dos vários tipos de drogas pressupõe situações do indivíduo, do grupo, do bairro, da cidade, da região, do Estado-nação e do mundo globalizado.

Segundo a autora é necessário modernizar o discurso preventivo, "a construção do discurso sobre as drogas, o procedimento do comentário, de repetição de conceitos já enunciados e aceitos como verdadeiros, tem como objetivo controlar o acaso que surge naquela participação, limitando o pensar autônomo" (ACSELRAD, 2005, p. 185). Nesse caminho, o discurso sobre as drogas na sua busca pela abstinência é repetido nas legislações atuais, tanto é que o Estado declarou o fim da política de redução de danos e a adoção da abstinência como forma de tratamento. Foi modificado em aparência e modernizado em parte para continuar sendo o mesmo. Para Acselrad (2005, p. 186) "os usos mudam com o tempo", da mesma forma como acontece com o consumo de drogas. Segundo a autora, a educação é o caminho mais viável contra o abuso de drogas:

\footnotetext{
Apesar de tantos argumentos, o discurso da abstinência prevalece, criminaliza o uso de certas drogas, não favorece reflexão e ação responsável - as 'verdades' que sustentam o discurso preventivo repressivo tornam-se uma pedra no meio do caminho da educação (ACSELRAD, 2005, p. 186).
}

Para a autora (2005), na construção de um modelo de prevenção e tratamento, a noção da droga como produto que invade o sujeito paciente, em um ambiente favorável à sua multiplicação e afirma a noção de supostos sujeitos frágeis, dá origem às campanhas de repressão ao consumo de drogas, que seguem o mesmo princípio da proteção da saúde pública e do indivíduo e ajudá-los a resistir, impondo de forma autoritária medidas preventivas e repressivas, consideradas vitais “à preservação da saúde, à tranquilidade dos lares, à produção, à segurança pública” (ACSELRAD, 2005, p. 187).

Segundo ensina Acselrad (2005, p. 187) "essa linguagem ajuda a construir uma imagem negativa da própria condição de existência do usuário, como alguém que ameaça a tranquilidade coletiva". A autora conclui que o objetivo da política antidrogas historicamente buscou, no discurso médico ou repressivo, justificativas para um controle sobre os sujeitos. 
Carl Hart (2014), neurocientista americano, afastando-se da racionalidade moralizadora, ensina que os problemas sociais é que agravam a questão do uso de drogas. Segundo o autor descriminalizar as drogas não causaria danos piores do que os que já são percebidos nas sociedades, ao contrário, poderia contribuir para que houvesse mais igualdade social e educação nos países.

O autor acredita que as drogas não são responsáveis pela violência urbana e tem o papel de "bode expiatório" de governos que não estão comprometidos com políticas sociais para combater a desigualdade social e garantir acessos e oportunidades a seus cidadãos mais carentes. Para o neurocientista, o crack é o menor dos problemas nas crackolândias.

Por meio de experimentos em laboratório, Hart (2014) concluiu que quando são oferecidas apenas drogas a cobaias, elas se viciam e chegam até a morrer por causa do consumo excessivo, e quando lhes são oferecidas outras opções, elas não escolhem sempre usar as drogas e preferem as outras opções. Desse modo, o autor sugere que há como usar substâncias como crack, cocaína e maconha sem se viciar. Defende o autor que a população deve entender que apenas $20 \%$ das pessoas que consomem drogas precisam de tratamento.

O efeito relacionado ao consumo das drogas pode ser visto como uma guerra, imposta por uma política pública que o Estado define, para controlar as situações de consumo e comercialização, fazendo parte de uma questão social de uso ou consumo abusivo, de acumulação do capital e de modos de exercício do poder político, sendo certo que em anos de proibição o Estado não exterminou ou sequer reduziu o consumo e o comércio clandestino.

No Brasil, a atual lei de drogas, lei 11.343/06, prevê medidas contra o comércio e consumo de drogas. Em relação ao porte de drogas para consumo pessoal, longe dos processos de descriminalização sustentados por políticas de redução de danos ocorridos em inúmeros países europeus nos últimos anos, observa-se a manutenção de sistema proibicionista estruturado na reciprocidade punitiva entre penas restritivas de direitos e medidas de seguranças atípicas, aplicadas aos usuários.

Apesar de estabelecer formalmente a impossibilidade de aplicação de pena carcerária aos sujeitos envolvidos com o consumo de drogas, as medidas terapêuticas, adotadas pela 
justiça terapêutica, conservam mecanismos penais de controle, com similar efeito moralizador e normalizador e obstruem a implementação de políticas públicas saudáveis.

Assim, de acordo com os princípios proibitivos existentes na lei de drogas e em busca da repressão do consumo e comercialização clandestina de drogas, é lançada pelo Estado uma guerra, que como toda batalha é fundamentada na morte, na violência, no desrespeito aos direitos fundamentais dos seres humanos, em especial o consumidor de drogas, que é estigmatizado como delinquente e sofre as sanções impostas pelo Estado, mesmo que não cause prejuízos a terceiros.

Neste mesmo caminho é que a guerra declarada contra as drogas é mais nociva que o consumo de drogas, pois viola os direitos humanos, provoca violência, causa morte e destruição de famílias, além de lotar os estabelecimentos prisionais de cidadãos usuários de drogas, que por portarem ilicitamente substância psicoativa, muitas vezes para o próprio consumo, foram considerados delinquentes ou traficantes.

Segundo Karam (2013), o custo mais elevado da criminalização das drogas é a sangrenta e violenta guerra de repressão imposta pelo Estado e a punição dos consumidores de drogas, por uma infração de perigo abstrato, o que claramente afronta os princípios constitucionais e os direitos humanos.

De acordo com a autora, o principal objetivo da guerra às drogas brasileira é claro: eliminar a comercialização e o consumo a qualquer custo e assim a explícita guerra contra as drogas demonstra o descompromisso com os direitos fundamentais dos cidadãos, sendo lógico que guerras e direitos humanos são naturalmente incompatíveis. A toxicomania assim é definida como uma delinquência (infração, delito ou crime) e como uma doença (dependência química) que compete ao Estado e à medicina eliminar e tratar.

Conforme narra Karam (2013), as leis da guerra contra as drogas, à proibição e a criminalização, pretendem proteger os indivíduos deles mesmos, com a desvantagem de punir todos pelos excessos de alguns. Do ponto de vista jurídico, as leis de proibição das drogas, que tem como alvo a criminalização e a punição do consumidor são geralmente inconstitucionais, pois violam princípios de direitos humanos como a própria liberdade de opinião e de consumo. 
O Estado e as leis, em determinados casos, não podem proibir as ações de um cidadão que causem danos somente a ele próprio, ou à sua integridade. Enquanto o consumidor se mantiver solitário no seu consumo, e não forçar ninguém a fazer o mesmo que ele, ou não causar prejuízos a terceiros, esse ser humano não causa dano senão a ele próprio. A sua condenação a qualquer tipo de penalidade constitui uma violação dos direitos humanos, uma vez que, como já dito, não existe ofensividade na ação de consumir drogas (KARAM, 2013).

Segundo Carvalho (2013), podemos afirmar que a guerra contra as drogas é anticonstitucional porque viola os direitos e as liberdades fundamentais da cidadania e da democracia, mas também que a política pública parte de premissas e postulados falsos, como a proteção da saúde pública, mesmo no caso da dependência (toxicomania). Basta pensar no trabalho da medicina, apesar da sua mercantilização, e das políticas sociais centradas na dignidade e liberdade do cidadão cujo objeto é o tratamento do toxicômano. A criminalização de qualquer ação ou omissão deve estar sempre referida a uma ofensa relevante a um bem jurídico alheio, relacionado ou relacionável a direitos individuais concretos, ou à exposição deste bem jurídico a um perigo de lesão concreto, direto e imediato.

Ensina Karam (2013) que após anos da globalizada proibição o único resultado visível é que as substâncias proibidas foram se tornando mais baratas, mais potentes, mais facilmente acessíveis e mais diversificadas. A guerra, as mortes, a violência e as prisões e aplicação de penalidades alternativas aos usuários de drogas, nem sequer afetam o fornecimento de drogas, o mercado clandestino e o consumo abusivo ou não. Contudo, com os princípios adotados pela política repressiva, as garantias constitucionais dos usuários de drogas, como a liberdade e autonomia, são esquecidas pela lógica moralizadora, mesmo que a conduta do consumidor não cause danos a terceiros.

\section{A TEORIA GARANTISTA DE LUIGI FERRAJOLI E A INCONSTITUCIONALIDADE DA CRIMINALIZAÇÃO DO USO E DO USUÁRIO DE DROGAS.}


A teoria garantista de Ferrajoli tem por fundamento a tutela das liberdades individuais frente às várias formas do exercício arbitrário de poder estatal, o que também deve ser considerado na aplicação das penalidades relacionadas à lei de drogas. Segundo Luigi Ferrajoli (2002), a polêmica relacionada ao consumo de drogas pode envolver dois aspectos, um do ponto de vista emotivo, pois a sociedade ainda mantém uma visão estereotipada e preconceituosa acerca do uso de substâncias ilícitas, e outro do ponto de vista constitucional, uma vez que a criminalização das drogas não se mantém por força da desobediência da lei frente aos princípios formadores do Estado punitivo, que se reserva a tutelar o interesse da sociedade como um todo.

O direito penal é o ramo do direito que tem a finalidade de proteger os bens jurídicos mais importantes e necessários para a manutenção da vida em sociedade, ou seja, tem por objetivo tutelar os bens mais relevantes à existência do corpo social. Nesse sentido é que a sanção penal revela-se como a ultima ratio da política social e sua missão é proteger e resguardar bens jurídicos. Sobre isso, Ferrajoli (2002, p. 178), afirma que "o direito penal não possui a tarefa de impor ou reforçar a (ou uma determinada) moral, mas sim, somente de impedir o cometimento de ações danosas a terceiros". De acordo com o autor, a sanção penal deve ser imposta quando ocorrer ações relevantemente danosas a terceiros, o que não ocorre no caso do consumo de drogas, quando, por exemplo, o usuário não atinge nenhum bem relevante de outra pessoa.

Nos dias atuais, o direito penal se relaciona principalmente com temas de muita importância para a sustentação do próprio sistema penal, como a proteção dos bens jurídicos mais relevantes, os direitos humanos, a evolução do conceito de ação e conduta, e outros conceitos. De acordo com Bittencourt (2000), a tendência do direito penal foi direcionar-se no sentido da despenalização, colidindo com o movimento de brutalidade da lei penal, que foi marcado pela conotação moral e emocional da lei e uma forte intenção de manipular a opinião pública. Essa atividade se manifesta através da criação de uma lei fortemente simbólica, sem qualquer possibilidade útil de aplicação, chocando-se com a tendência da proposta de um direito penal mínimo.

Foucault (1987) ensina que o direito penal não pode ser uma ciência imutável e deve se submeter aos paradigmas dominantes. Na obra Vigiar e Punir, o autor narra que o poder de 
punir e julgar se apoia e recebe suas regras de aplicação de pena, enquanto forma de coerção e suplício, disciplina e aprisionamento do ser humano por desvios de normas de comportamento.

Segundo o autor, a forma de punir e disciplinar os seres humanos se manifesta nas escolas, indústrias e Forças Armadas modernas, como forma de exercer o poder para produzir sujeitos, que funcionem como engrenagens da nova sociedade pós-absolutismo. Assim, o Estado objetiva transmitir a imagem de que esse poder punitivo exercido sobre os indivíduos é bom, que pretende apenas corrigir e reformar a pessoa, mas nunca apenas puni-la.

Foucault (1987) narra que o humanismo pregado pelo Iluminismo é um disfarce para perpetuar a estrutura do poder e da verdade. Contudo, o poder soberano do Estado suprimia qualquer forma de expressão dos direitos fundamentais inerentes à própria existência da pessoa enquanto sujeito de direitos. Assim, a deturpação dos sentidos ideológicos e a atribuição de interpretações completamente contrárias aos princípios democráticos e humanistas, acabam por descaracterizar qualquer benevolência da aplicação de penas desumanas. Isso também pode se relacionar com a aplicação de qualquer tipo de penalidade ao usuário de drogas, que, como já mencionado, ao consumir a substância não coloca em risco jurídico bens relevantes de outras pessoas.

Nessa situação, surge a preocupação de se estabelecer um direito penal mínimo que respeite, de forma objetiva, o direito à vida, à liberdade e à autonomia de escolhas, assentados nas garantias constitucionais e nos princípios advindos, expressa ou implicitamente, da Carta Magna, tais como: o princípio da dignidade da pessoa humana, da ofensividade, da insignificância, princípio da legalidade, o princípio da intervenção mínima, o direito à liberdade, à intimidade, à autonomia, dentre outros.

Roberti (2007), explica que no princípio da intervenção mínima o legislador, observando as mudanças ocorrentes na sociedade, deixa de dar importância a bens que antes tinham maior relevância, retirando do ordenamento jurídico certos tipos incriminadores. Isso implicará em uma interferência mínima do direito penal no convívio social encontrando espaço apenas quando outros ramos do direito não forem capazes de proteger aqueles bens de maior importância. 
A teoria garantista de Ferrajoli aposta em um resultado alto: a elaboração de um sistema geral do garantismo ou a construção das colunas mestras do Estado de direito, que "tem por fundamento e fim a tutela das liberdades do indivíduo frente às variadas formas do exercício arbitrário de poder, particularmente odioso no direito penal”. (FERRAJOLI. 2002, p. 08).

Os princípios utilizados por Ferrajoli para desenvolver o modelo garantista clássico são a legalidade estrita, a materialidade e a lesividade dos delitos, a responsabilidade pessoal, o contraditório entre as partes e a presunção de inocência, que são frutos da tradição iluminista e liberalista, mas também se incluem nessa tradição as doutrinas de direito naturais, as teorias contratualistas, a filosofia racionalista e empirista, as doutrinas políticas da separação de poderes e supremacia da lei, o positivismo jurídico e as concepções utilitaristas do direito e da pena. Estas definições compõe o modelo garantista de direito penal.

Ferrajoli (2002) utiliza onze termos para a formulação dos princípios da teoria, sendo eles: pena, delito, lei, necessidade, ofensa, ação, culpabilidade, juízo, acusação, prova e defesa. Segundo o autor, cada um destes termos, excluindo-se a pena, designa uma condição necessária para a atribuição de condenação dentro do modelo do direito penal. A adoção do modelo garantista, começando pelo garantista no grau máximo, pressupõe, assim, uma opção éticopolítica a favor dos valores normativamente tutelados. Isso não impede o caráter descritivo e não normativo de sua análise teórica e, sobretudo, de seu uso.

O sistema garantista também foi denominado cognitivo ou de legalidade estrita e aborda dez princípios que definem o modelo garantista de direito ou de responsabilidade penal e podem ser vistos como o princípio da retributividade da pena em relação ao delito; o princípio da legalidade, no sentido lato e no sentido estrito; o princípio da necessidade e da economia do direito penal; o princípio da lesividade do evento; o princípio da materialidade da ação; o princípio da culpabilidade pessoal; o princípio da jurisdicionariedade, também no sentido lato e no sentido estrito; o princípio acusatório e da separação entre juiz e acusação; o princípio do ônus da prova e da verificação; o princípio do contraditório, da defesa, ou da falseabilidade.

A teoria garantista, que dialoga e reconstrói o pensamento positivista da Teoria Pura do Direito de Kelsen ${ }^{3}$, visa acentuar e assegurar as garantias formais (constitucionais) aos

\footnotetext{
${ }^{3}$ A teoria pura do direito é o ápice do desenvolvimento do positivismo jurídico. Para essa doutrina, o conhecimento é restrito aos fatos e às leis que os regem, isto é, nada de apelar para a metafísica, a razão ou à religião.
} 
indivíduos que se sujeitam à aplicação de uma sanção penal. O garantismo busca também submeter a controle o poder punitivo do Estado, exigindo precisa vinculação aos princípios da previsibilidade, igualdade, proporcionalidade e segurança jurídica, sem descuidar da defesa do direito penal mínimo ou princípios da intervenção mínima.

Partindo do direito penal foi que Luigi Ferrajoli iniciou uma reflexão que se transformou em sua teoria do garantismo penal. Segundo o nosso autor o modelo penal garantista se encontra recusado na prática, causando divergências entre a normatividade do modelo constitucional e a ausência de efetividade nos níveis inferiores, transformando tal modelo em um tipo de "fachada ideológica".

É pela defesa do Estado de Direito e do ordenamento democrático que nasce o garantismo jurídico. A teoria do garantismo consiste na proposição de uma nova teoria do direito, onde são acrescidos alguns novos entendimentos em relação à teoria clássica e pura do direito de Hans Kelsen, surgindo com a intenção de converter o entendimento em relação à vigência, validade e eficácia da norma jurídica, bem como o respeito e a prevalência da Constituição Federal e dos princípios constitucionais.

O garantismo, segundo Ferrajoli (2002), é uma teoria que busca enfatizar e assegurar as garantias formais aos indivíduos que se encontrem processados ou condenados, como forma de resposta ao acentuado poder punitivo do Estado e atua como maximizadora dos direitos e garantias fundamentais aos cidadãos, e ao mesmo tempo como minimizadora do poder de punir do Estado, baseando-se no respeito à dignidade da pessoa humana e nos direitos fundamentais.

Ferrajoli demonstra que as acepções do garantismo também podem servir de princípios para uma teoria geral do garantismo, que deve ser aplicada não só ao Direito Penal, mas a todos os outros ramos do direito. Nesse caminho, o autor busca estabelecer uma teoria do garantismo a partir de três acepções diferentes, mas que se relacionam.

Na primeira acepção a teoria garantista é entendida como um modelo normativo de direito, especialmente do direito penal, estruturando-se a partir do princípio da legalidade, que de acordo com Ferrajoli é a base do Estado de Direito, ou seja, toda a atuação do poder judiciário na liberdade da pessoa humana deve estar estritamente respeitando os princípios legais e constitucionais. 
Em sua segunda acepção o termo além de ser visto como um modelo normativo de direito, entendido nos planos político, jurídico e epistemológico, também pressupõe uma teoria que busque explicar os problemas de validade e efetividade das normas. Ferrajoli reconhece que:

\begin{abstract}
Em um segundo significado, 'garantismo' designa uma teoria jurídica da 'validade' e da 'efetividade' como garantias distintas não só entre si, mas, também, pela 'existência' ou 'vigor' das normas. Neste sentido, a palavra garantismo exprime uma aproximação teórica que mantém separados o 'ser' e o 'dever ser' no direito; e, aliás, põe como questão teórica central, a divergência existente nos ordenamentos complexos entre modelos normativos (tendentemente garantistas) e práticas operacionais (tendentemente antigarantistas), interpretando-a com a antonomia dentro de certos limites fisiológicos e fora desta patológica - que subsiste entre validade (e não efetividade) dos primeiros e efetividade (e invalidade) das segundas) (FERRAJOLI, 2002, p. 684).
\end{abstract}

A terceira acepção estabelecida pelo termo garantismo é de uma busca de justificativa externa dos parâmetros garantistas adotados internamente pelos Estados. Assim, o autor narra que "o garantismo designa também uma teoria filosófica política que requer do direito e do Estado o ônus da justificação externa, com base nos bens e nos interesses dos quais a tutela ou a garantia constituem a finalidade" (FERRAJOLI, 2002, p. 685). O autor observa que:

\footnotetext{
Neste último sentido o garantismo (pressupõe) a doutrina laica da separação entre direito e moral, entre validade e justiça, entre ponto de vista interno e ponto de vista externo na valoração do ordenamento, ou mesmo entre o ser e o dever ser do direito. E equivale à assunção, para os fins da legitimação e da perda da legitimação éticopolítica do direito e do Estado, do ponto de vista exclusivamente externo FERRAJOLI (2002, p. 685).
}

Ferrajoli, ao apresentar os três significados do garantismo, que antes somente se relacionavam ao direito penal, concluiu que a teoria do garantismo pode ter um alcance teórico e prático para todos os outros ramos do direito. $\mathrm{O}$ autor reconhece que a legitimidade dos comandos e práticas garantistas são de cunho ético-político externos, sendo que estes elementos são as bases fundamentais para o surgimento dos comandos jurídicos no Estado.

Assim, busca uma tentativa de, dentro do normativismo jurídico, ampliar o leque de possibilidades para a garantia dos direitos previstos constitucionalmente, fazendo da norma estatal um ponto de partida para a observação de sua adequação à realidade social, ou não. A teoria garantista oferece algumas soluções institucionais e se atenta em definir a dose certa de penalização do direito penal, incluindo princípios disciplinares fundamentais como o princípio 
da adequação social, da lesividade, da proporcionalidade, da legalidade, da responsabilidade, etc., objetivando alcançar uma nova qualidade processual que não seria abusiva ou excessiva, uma vez que a dignidade humana predomina como teleologia sobre a aplicação da lei penal, o que resulta, por exemplo, na idealização de uma justiça restaurativa em casos de menor gravidade.

Aplicando a Teoria Garantista de Luigi Ferrajoli na política de drogas adotada pelo Brasil, observamos que ao ser humano usuário de drogas, não é aplicada uma penalização proporcional ao ato cometido ou uma justiça restaurativa, uma vez que, mesmo não cometendo qualquer ato que viole a liberdade ou a propriedade de terceiro, pode receber penalidades e ser classificado pelo sistema penal como traficante.

No caso da proibição ao consumo de drogas vários princípios constitucionais e penais são violados pelo sistema repressivo, como o princípio da liberdade, da inviolabilidade da vida privada, da lesividade, da autonomia e da proporcionalidade. O usuário de drogas, em parte dos casos, não necessita cometer qualquer tipo de crime para adquirir a droga que irá consumir, a não ser se envolver com o mercado ilegal do tráfico, e mesmo assim pode sofrer penalização do Estado por consumir substância ilegal.

Segundo Ferrajoli (2002), a teoria garantista visa preservar os direitos individuais e sociais dos seres humanos, que são direitos fundamentais assegurados constitucionalmente e podem ser reconhecidos como o direito à intimidade; à privacidade; à autonomia; à liberdade; e acima de tudo, o direito à vida e à qualidade igualitária de se viver, além dos direitos à saúde e assistência social. Assim, De acordo com a teoria, a aplicação de qualquer penalidade ao consumidor de drogas é um ato abusivo do Estado, uma vez que a conduta do consumo de drogas é penalizada, mesmo que não coloque em risco bens de terceiros, sendo certo que não existe ofensividade na conduta e proporcionalidade na pena aplicada.

A lei de drogas adotada pelo Brasil dispõe que o sujeito flagrado na posse de drogas, mesmo que para consumo pessoal, será submetido às penas de advertência sobre os efeitos das 
drogas, prestação de serviços à comunidade e medida educativa de comparecimento a programa ou curso educativo ${ }^{4}$. Nesse caminho, prescreve a lei 11.343/2006, em seu artigo 28 que:

\footnotetext{
Artigo 28. Quem adquirir, guardar, tiver em depósito, transportar ou trouxer consigo, para consumo pessoal, drogas sem autorização ou em desacordo com determinação legal ou regulamentar será submetido às seguintes penas:

I - advertência sobre os efeitos das drogas;

II - prestação de serviços à comunidade;

III - medida educativa de comparecimento a programa ou curso educativo.
}

Assim, observa-se que mesmo o consumidor de drogas não violando direito de outra pessoa é condenado a uma penalização de advertência, prestação de serviços ou medidas educativas, o que contraria totalmente os princípios constitucionais mencionados e demonstra a abusividade do poder punitivo do Estado, que deixa de observar os princípios da ofensividade, adequação social e da proporcionalidade ditados na teoria garantista e adotados no processo penal.

Aplicando-se os direitos e garantias acima mencionados à política de repressão ao consumo de drogas notamos que, ao criminalizar o consumo, e por consequência o usuário de drogas, o Estado está violando e desrespeitando garantias constitucionais, especificamente o direito à liberdade, à privacidade, à intimidade e também o direito à autonomia de o cidadão consumir substância que deseje desde que não cause prejuízos a terceiros. É o que determina o artigo $5^{\circ}$, incisos VI e X da Constituição Federal, quando trata sobre os direitos e garantias fundamentais, aos direitos sociais e prevalência dos direitos humanos. Assim, vejamos:

Artigo $5^{\circ}$. Todos são iguais perante a lei, sem distinção de qualquer natureza, garantindo-se aos brasileiros e aos estrangeiros residentes no País a inviolabilidade do direito à vida, à liberdade, à igualdade, à segurança e à propriedade, nos termos seguintes:

VI - é inviolável a liberdade de consciência e de crença, sendo assegurado o livre exercício dos cultos religiosos e garantida, na forma da lei, a proteção aos locais de culto e a suas liturgias;

$\mathrm{X}$ - são invioláveis a intimidade, a vida privada, a honra e a imagem das pessoas, assegurado o direito a indenização pelo dano material ou moral decorrente de sua violação;

\$ $\mathbf{1}^{\mathbf{0}}$ As normas definidoras dos direitos e garantias fundamentais têm aplicação imediata.

\footnotetext{
${ }^{4}$ Sistema Nacional de Políticas Públicas sobre Drogas - Sisnad; prescreve medidas para prevenção do uso indevido, atenção e reinserção social de usuários e dependentes de drogas; estabelece normas para repressão à produção não autorizada e ao tráfico ilícito de drogas; define crimes e dá outras providências.
} 
Mesmo com as garantias constitucionais acima mencionadas, o usuário de drogas ainda sofre privações decorrentes do Estado. Nessa distorcida e estigmatizada visão social do usuário, demonstrada pelo artigo 28 da lei de drogas, haveria tipicidade formal para o delito de porte de droga (até mesmo quando para consumo próprio) eis que o legislador fez previsão expressamente para esse tipo de delito.

No entanto, não poderia o Estado, simplesmente criar um tipo genérico que interfere diretamente na liberdade dos cidadãos, como por exemplo, aqueles usuários de drogas de alta classe social, que nunca precisaram se envolver em outros tipos de crime para sustentar sua necessidade de consumo. Assim, no direito penal, cada conduta que seja considerada como contrária à sociedade, harmonia social ou segurança jurídica, deve ser especificada e individualizada, prevendo garantias para a sociedade e para o autor da infração penal.

A tipicidade no ponto de vista garantista rompe os conceitos de uma simples subsunção da conduta à letra da lei penal, já que possui como fundamentos os princípios e normas constitucionais. Ferrajoli (2002) estabelece um conjunto ordenado de normas e valores como a legalidade, a ofensividade, a adequação da pena ao ato praticado, sendo necessário que a ideia existente de tipicidade se adeque a nova ordem constitucional com a concepção garantista, afastando assim a concepção legalista do direito penal.

Segundo Karam (2013), realizando a analise do artigo 28 da lei 11.343/06, observamos que o bem jurídico a ser tutelado não mais comporta proteção penal, como por exemplo, a saúde pública. Outros mecanismos dentro do direito podem e devem controlar o consumo de substâncias entorpecentes. A descriminalização, por sua vez, não impede a imposição de restrições de natureza não penal, que podem ser necessárias. Deve haver uma limitação administrativa e civil, como por exemplo, a proibição de se consumir drogas em lugares públicos ou por pessoas menores de dezoito anos. Porém, no ambiente particular/privado, não há sentido em fazer tal proibição.

Se uma pessoa pode tomar seu vinho, sua vodka, sua cerveja, ou utilizar seus medicamentos entorpecentes, porque outras pessoas não podem fumar seu "baseado"? De acordo com Karam (2013), é inconstitucional fazer a proibição de certas substâncias, sendo que outras, que também causam efeito psicológico, e por vezes efeitos mais degradantes à saúde do consumidor e à saúde pública, são liberadas. 
No caso da lei de drogas, Karam (2013) narra que a suposta alegação de proteger a saúde pública, como bem jurídico tutelado, cria, de forma contrária, com a proibição, maiores riscos à integridade física e mental dos consumidores, sendo que são impostos à clandestinidade da distribuição das drogas e ao consumo abusivo. A criminalização somente favorece a ausência de controle de qualidade das drogas comercializadas, o que aumenta a possibilidade de adulteração e impurezas, e daí, surgem outros riscos decorrentes. A criminalização favorece também o mercado ilegal, o corrompimento dos agentes estatais, a violência, as mortes decorrentes da guerra, a violação de direitos e etc.

Ferrajoli (2002), afirma que são inofensivas as proibições incapazes de surtir um mínimo efeito intimidatório na sociedade como a proibição uso de drogas. Reconhece que o uso de drogas, dada sua natureza (inconstitucional) de crime de perigo abstrato, é um dos delitos que apresenta a mais alta taxa de cifra negra, sendo somente uma parte dos usuários que são flagrados pelo direito penal. Deste modo, a aplicação aleatória da norma faz com que a sensação de segurança da sociedade não seja ameaçada com a ocorrência do delito e possibilita que a sociedade acredite que aquelas condutas sejam irrelevantes para o direito penal, logo, qualquer condenação passa a ser vista como uma condenação injusta.

O autor ao tratar da relevância e ofensividade ao bem jurídico tutelado pelo direito penal toma por base a ideia de nullum crimen sine injuria, ou seja, não existe infração penal sem ofensa ou ataque não só efetivo, mas também relevante. Esta ideia tem como princípios os postulados garantistas observados por meio dos princípios constitucionais que se relacionam com a concepção democrática do Estado de Direito. Esta mesma interpretação pode ser estendida ao princípio da insignificância quando observamos que não há bem jurídico penalmente relevante capaz de manter o tipo penal de porte ou consumo de droga dentre as condutas proibidas pelo direito penal.

O princípio da insignificância, conhecido também como princípio da bagatela, tem a finalidade de eliminar ou afastar a tipicidade penal. Significa dizer que o ato praticado não é considerado como crime. Assim, a aplicação desse princípio garante a absolvição do réu e não somente a diminuição e substituição da pena. O princípio da insignificância tem por finalidade auxiliar o intérprete quando procede a análise do tipo penal, para que seja desconsiderado do âmbito da incidência da lei penal certas situações vistas como bagatela (GOMES, 2006). Assim, 
a avaliação qualitativa e quantitativa do ato injusto supostamente cometido, permite que o fato penalmente insignificante seja excluído da tipicidade penal, mas possa receber um tratamento adequado se for necessário, de outros ramos do direito.

Tratando-se do delito de posse de drogas para consumo, conforme disciplinado no artigo 28 da lei de drogas, transcrito anteriormente, não se pode chegar a uma conclusão que seja distinta da insignificância, onde não é possível haver incidência de penalidade sobre o agente, eis que por incidência do princípio da insignificância ocorre a exclusão da tipicidade penal do fato.

Segundo Gomes (2006, p. 157), é possível se falar em duas modalidades distintas de infração insignificantes, "a primeira reside na insignificância da conduta, neste caso, desaparece o juízo de desaprovação da conduta: e a segunda no resultado, já que não há que se falar em resultado jurídico desvalioso".

De acordo com o autor, a posse de drogas para consumo está classificada dentro dos chamados delitos de posse, categoria do direito penal. Nesse caminho, as condutas desta natureza demandam, para que seja consumado o delito, a constatação ofensividade ou periculosidade, do próprio objeto material da conduta, ou seja, se a droga apreendida não reúne capacidade ofensiva alguma, em razão da pequena quantidade apresentada, não há que se falar em infração, pois não existe uma conduta penalmente relevante.

Nos casos de posse de drogas para consumo, a consequência natural da aplicação do princípio da insignificância é a exclusão da responsabilidade penal dos fatos ofensivos de pouca importância ou pequena lesividade. São conceituados como fatos meramente atípicos. Se a tipicidade penal é a adição da tipicidade formal e da tipicidade material, não restam incertezas de que, pela força do princípio em comento, fatos ofensivos de pouca importância ou pequena lesividade são atípicos, isso porque, não há desaprovação da conduta e não existe resultado jurídico desvalioso.

Embora a maioria das doutrinas penalistas reconheçam a atipicidade do delito de porte de drogas por ser uma conduta de bagatela e na maioria dos casos, não oferecer um perigo relevante, a jurisprudência brasileira não adota a incidência do princípio da insignificância, mas sim a violação aos direitos que tratam da inviolabilidade à vida privada, à honra, imagem, o 
direito à intimidade e o direito do individuo se autodeterminar, sendo livre a praticar qualquer conduta que não ultrapasse sua esfera íntima, tendo em vista a prática de supostas ações de perigo abstrato. Nesse caminho, tramita no STF o Recurso Extraordinário n. $635.659^{5}$ que trata sobre a inconstitucionalidade do artigo 28 da lei de drogas, com base em princípios constitucionais da intimidade, vida privada, autonomia e proporcionalidade.

No mesmo caminho, é importante também relacionar o porte de drogas para consumo com o princípio da lesividade e o princípio da intervenção mínima do direito penal, que são como duas faces de uma moeda, onde, de um lado, a intervenção mínima permite a interferência do direito penal somente quando estivermos diante de ataques a bens jurídicos relevantes, de outro, o princípio da lesividade estabelece quais as condutas que merecerão ser incriminadas.

O princípio da lesividade exige que do fato praticado ocorra lesão ou perigo de lesão ao bem jurídico tutelado e demonstra a impossibilidade de atuação do Estado punitivo quando um bem jurídico relevante de terceiros não esteja sob ameaça de lesão ou, seja efetivamente lesado. Aquilo que for da natureza do sujeito deverá ser respeitado pela sociedade e pelo Estado sob o enfoque do princípio da lesividade, mesmo que seja o consumo de drogas. Ferrajoli (2002, p. 383-384) narra que: “o princípio da lesividade se assume como critério de minimização das proibições penais, equivalente a um princípio de tolerância tendencial da desviação, idôneo para reduzir a intervenção penal ao mínimo necessário".

O princípio da lesividade também pode ser relacionado com a função de impedir que o agente seja punido por aquilo que ele é, e não pelo que fez, como no caso do usuário de drogas, que não lesiona bem relevante de terceiros, por exemplo. Greco (2006), ao tratar sobre o princípio da lesividade demonstra que em outra vertente do princípio estudado, o que se busca é afastar da incidência de aplicação da lei penal àquelas condutas que, embora desviadas, não afetem qualquer bem jurídico de terceiros. Ao relatar sobre estas condutas desviadas, aquelas que a sociedade trata com certo desprezo, ou mesmo repulsa, mas que, embora reprovadas sob o aspecto moral, não repercutem diretamente sobre qualquer bem de terceiros.

Por consequência, a conduta do consumidor de drogas está amparada pelo princípio da lesividade penal, onde, se um sujeito em pleno gozo de suas faculdades mentais resolve, por

\footnotetext{
${ }^{5} \mathrm{RE} 635.659-\mathrm{RG} / \mathrm{STF}$.
} 
vontade, fazer uso de drogas, sem que ofereça risco e prejuízos a terceiros, ou que atente para bens jurídicos alheios e relevantes, não há razão para que a conduta seja criminalizada ou penalizada, conforme sustenta Bittencourt (2004, p. 20): “somente se justifica a intervenção estatal em termos de repressão penal se houver efetivo e concreto ataque a um interesse social relevante, que represente, no mínimo, perigo concreto ao bem jurídico tutelado”.

No Brasil, o consumidor de drogas tem sua faculdade de consumir demarcada pelas penalizações do artigo 28 da lei de drogas, uma vez que, conquanto não sejam previstas penas privativas de liberdade, existem penalidades de outras naturezas que devem ser aplicadas caso o agente cometa alguma das (infr)ações descritas no tipo penal, mantendo-se ignorada a acepção garantista do princípio da lesividade, que é elementar para o direito de punir.

A política de drogas, desde o início da criminalização do uso destas substâncias, incrimina o consumo opondo-se efetivamente ao princípio da lesividade a as atuais recomendações político criminais. Segundo Bianchini (2007), existe no princípio da lesividade a concepção e a proteção da liberdade individual o que decorre do Estado Democrático de Direito, em que se funda o respeito da autodeterminação individual cuja penetração do Estado é proibida, o que deveria ser observado na adoção de uma política de drogas. Tal princípio reitera a preocupação com o exercício da liberdade individual, desde que não comprometa a liberdade de terceiros.

Assim, deve existir uma completa tolerância em relação a condutas que exprimam o modo de ser, a consciência interna e os atos privados do cidadão que não cause nenhum mal à sociedade. É aceitar e respeitar a forma como cada pessoa quer conduzir a sua vida, deixar de estigmatizar o usuário de drogas como tóxico-delinquente e tolerar a ideia de que pessoas, nas mais diversas classes sociais, consomem vários tipos de drogas, legais ou ilegais, sentem prazer em consumir, da mesma forma que cada pessoa tem uma relação diferente com cada tipo de droga.

A presença dos princípios da liberdade, da lesividade e outros princípios inerentes ao Estado Democrático, mostram uma aptidão no sentido de limitar a atuação do Estado na penalização do usuário de drogas, o que não se compatibiliza com impunidade, podendo ser prevista e reservada à aplicação de outros tipos de sanção. 
Trata-se de tolerância e respeito ao direito do cidadão em consumir drogas, direito à vida privada, à liberdade, às suas próprias escolhas, desde que não violem direitos de terceiros, o que representa uma base fundamental na sociedade pluralista. Nesse caminho, Carvalho afirma que:

\begin{abstract}
Nenhuma norma penal será legítima se intervier nas opções pessoais, impondo aos sujeitos determinados padrões de comportamento ou reforçando determinadas concepções morais. A secularização do direito e do processo penal, frutos da recepção constitucional dos valores do pluralismo e da tolerância à diversidade, blinda o indivíduo das intervenções indevidas na esfera da interioridade. Assim, está garantido ao indivíduo a possibilidade de plena resolução sobre os seus atos, desde que sua conduta exterior não afete (dano) ou coloque em risco factível (perigo concreto) bens jurídicos de terceiros. Apenas nestes casos (dano ou perigo concreto) haverá intervenção penal legítima (CARVALHO, Salo. 1996. p. 281).
\end{abstract}

Ainda, segundo o autor, em analise ao artigo 28 da lei de drogas, observamos que as infrações ali descritas são classificadas como infrações de mera conduta, bastando-se apenas a desvalorização desta conduta para a configuração da prática delituosa, não necessitando demonstrar nenhum perigo de dano concreto, o que não pode ser concebido no ordenamento penalista atual, eis que a lesão de um bem jurídico ou sua exposição a perigo de dano é fundamental para o interesse de punir.

O constitucionalista brasileiro Streck (2001) afirma que para a concretização do princípio da lesividade ou ofensividade, o Estado não pode punir uma conduta que não cause dano ou perigo de lesão, caso contrário punirá uma conduta abstrata, neste caminho observese:

\footnotetext{
Ora, será demais lembrar que somente a lesão concreta ou a efetiva possibilidade de lesão imediata a algum bem jurídico é que pode gerar uma intromissão penal do Estado? Caso contrário, estará o Estado estabelecendo responsabilidade objetiva no direito penal, punindo conduta in abstracto, violando os já explicitados princípios da razoabilidade, da proporcionalidade e da secularização, conquistas do Estado Democrático de Direito (STRECK, 2001. p. 54).
}

Assim, segundo o autor, os delitos de perigo abstrato, como a criminalização do consumo de drogas, violam, além do princípio da lesividade e de outros princípios constitucionais, o princípio da inocência, uma vez que atribuiu ao consumidor uma presunção abstrata de perigo social, impulsionada com bases do positivismo do século XIX, aparentando ser, o direito penal, um ramo do direito totalitário em visível oposição à democracia, tolerância 
e respeito às liberdades individuais, entrando em conflito direito com a teoria garantista do direito penal contemporâneo.

Carvalho (2010), dita que não houve descrmininalização do uso de drogas, pois o artigo 28 da atual lei de drogas prevê penalidades para usuários, mantendo as condutas de consumo criminalizadas, sendo alteradas apenas as penas previstas, impedindo em qualquer caso, que não seja de tráfico de drogas, a pena de prisão, assim:

Não ocorreu processo de descriminalização do porte para consumo pessoal de drogas porque o Art. 28 da Lei de Drogas mantém as condutas dos usuários criminalizadas, alterando apenas sanção prevista, impedindo, mesmo em caso de reincidência (Art. $28, \S 3^{\circ}$ ), a pena de prisão "quem adquirir guardar, tiver em depósito, transportar ou trouxer consigo, para consumo pessoal, drogas sem autorização ou em desacordo com determinação legal ou regulamentar será submetido às seguintes penas: I - advertência sobre os efeitos das drogas; II - prestação de serviços à comunidade; III - medida educativa de comparecimento a programa ou curso educativo (CARVALHO. 2010. p. 110).

A sustentação da política punitiva decorre de dois pontos relevantes, ser o delito previsto no artigo 28 da Lei 11.343/06 de perigo abstrato e ser a saúde pública o bem jurídico tutelado. Segundo Carvalho (2013), a identificação de bens jurídicos sob a chancela do Estado estabelece a espiritualização do valor ou interesse de tutela. No caso de drogas, inúmeros danos à saúde, à autonomia e a liberdade de pessoas, são lembrados pela política de saúde pública.

Neste sentido, notável argumentação foi desenvolvida em julgados referentes às normas incriminadoras no que tange ao porte de drogas para uso pessoal. O desembargador Milton dos Santos Martins, em dois votos vencidos proferidos em incidentes de inconstitucionalidade propostas em Recursos de Apelação perante o Tribunal de Justiça do Rio Grande do Sul, quando vigente a lei 6.368/76, expôs o problema:

Não é lícito ao Estado, dentro do sistema de liberdade democrática, punir o viciado, que é antes de tudo uma vítima. O art. 16 da Lei 6.368/76, punindo como infrator o viciado e doente, afronta a Constituição Federal, no que respeita à liberdade individual quanto ao uso de estupecaiente. (TJRS, Incidente de Inconstitucionalidade, AC 686062340, voto vencido Des. Milton dos Santos Martins. p.3.255). A preliminar é conhecida em suas razões. $\mathrm{O}$ art. 16 da lei de tóxicos tipifica proceder da esfera individual, restrita à pessoa, não interferindo com outrem. É, portanto, inconstitucional ao invadir e violar direitos fundamentais da pessoa. Não é o usuário que difunde o tóxico. Em vez de se prender quem anda com quantidades ínfimas para uso próprio, porque não se encontram as plantações dos traficantes, aqueles que fazem as desgraças dos outros. O usuário é vítima, não criminoso, que terá sua vida arruinada ainda mais, quando o Estado devia tratá-lo como doente, dar-lhe oportunidade de recuperação (TJRS, AC 687043661, P.3255/6). 
Junto aos argumentos decorrentes dos princípios da lesividade e da autonomia individual, os princípios da igualdade e da inviolabilidade da intimidade e da vida privada, permitem o reconhecimento da tese de inconstitucionalidade do artigo 28 da lei 11.343/06, tendo em vista as liberdades garantidas constitucionalmente e isso é discutido no STF no julgamento do Recurso Extraordinário 635.659, que, como já mencionado, trata sobre a inconstitucionalidade da criminalização do consumo de drogas.

A ofensa ao princípio da igualdade se faz presente nos momentos em que se estabelece distinção de tratamento penal (drogas ilícitas) e não penal (drogas lícitas) para usuários de diferentes substâncias, tendo ambas a potencialidade de determinar dependência física ou psíquica, e, algumas drogas lícitas tem poder de causar maiores prejuízos a seus consumidores e a terceiros, como o álcool por exemplo.

Os direitos à intimidade e à vida privada garantem a radical separação entre o direito e a moral. Nesse ponto de vista, nenhuma norma penal incriminadora será legítima se intervir nas opções pessoais ou se impuser padrões de comportamento que reforçam concepções morais. Nosso autor, Luigi Ferrajoli, estabelecendo uma proposta para o direito penal mínimo, observa que deveria ser anulada a lei de drogas, particularmente a iníqua proibição pelo uso pessoal de entorpecentes, em clara proteção às garantias constitucionais, senão vejamos:

\footnotetext{
Punindo o consumo, se acaba inevitavelmente na punição da toxicodependência enquanto tal, isto é, de uma trágica e infeliz condição pessoal de dependência e de sofrimento que exclui em grande parte, nos casos extremos, a própria vontade da pessoa. Não me ocuparei do fato de que uma similar criminalização de figuras sociais marginalizadas, que necessitam de assistência em lugar de punição, assinalam o reflexo de ordenamentos autoritários e, nos melhores dos casos, a nunca extinta ilusão repressiva que confia as penas a solução dos dramáticos problemas sociais e existenciais. O que é grave, sob o ponto de vista jurídico, a punição de uma condição pessoal enquanto tal, a qual contradiz o clássico princípio do Estado de Direito, aquele segundo o qual só pode ser punido apenas pelo que se fez e não pelo que se é como se age e não pela própria identidade (FERRAJOLI. 1991. p.137).
}

Dita o autor, que as normas proibitivas do uso pessoal de determinadas substâncias enunciam preceitos morais, representando a confusão pré-moderna dos séculos passados, onde as normas penais ocupam funções propagandísticas ou pedagógicas, afirmando ser uma grave violação aos direitos constitucionais, incluindo-se os direitos humanos, qualquer punição de uma condição pessoal, na qual o cidadão pode ser punido pelo que faz desde que prejudique 
terceiros, mas não pelo que é e desde que não prejudique a sociedade, como é o caso do consumidor de drogas.

Conforme narra Karam (2013), as leis da guerra contra as drogas, à proibição e a criminalização, pretendem proteger os indivíduos deles mesmos, com a desvantagem de punir todos pelos excessos de alguns. Do ponto de vista jurídico, as leis de proibição das drogas, que tem como alvo a criminalização e a punição do consumidor são geralmente inconstitucionais, pois violam princípios de direitos humanos como a própria liberdade de opinião e de consumo.

O Estado e as leis, em determinados casos, não podem proibir as ações de um cidadão que causem danos somente a ele próprio, ou à sua integridade. Enquanto o consumidor se mantiver solitário no seu consumo, e não forçar ninguém a fazer o mesmo que ele, ou não causar prejuízos a terceiros, esse ser humano não causa dano senão a ele próprio. A sua condenação a qualquer tipo de penalidade constitui uma violação dos direitos humanos, uma vez que, como já dito, não existe ofensividade na ação de consumir drogas (KARAM, 2013).

Nesse caminho, ao aplicarmos os princípios da teoria garantista na política proibicionista do consumo de drogas do Brasil, principalmente em relação aos direitos do cidadão consumidor de drogas, observamos que a aplicação de qualquer penalidade é inconstitucional e viola direitos e garantias individuais, como o direito à liberdade e à autonomia.

A aplicação de penalidades ao consumidor de drogas também viola princípios adotados no direito penal como o princípio da lesividade do ato e da proporcionalidade da pena aplicada. Isso ocorre porque, na maioria dos casos de consumo de drogas ilícitas o maior prejudicado é o próprio consumidor, ou seja, a conduta de consumir determinado tipo de droga não é potencialmente ofensiva para ser criminalizada, além de ser considerada crime de perigo abstrato.

\section{CONCLUSÃO}


As reflexões trazidas neste trabalho buscaram analisar as dificuldades encontradas na efetivação da política de criminalização do uso de drogas em relação ao consumo e ao tráfico de drogas e ao mesmo tempo à proteção dos direitos e garantias fundamentais elencados em nossa Constituição Federal de 1988, pelo fato de que, após muitos anos da declarada guerra contra as drogas, seus principais objetivos ainda encontram-se inalcançados, o fim ou ao menos a redução no tráfico e no consumo de drogas não ocorreu no Brasil.

Com base na legislação, as mudanças trazidas pela atual lei de drogas, n. 11.343/2006, ainda demonstram a penalização do consumidor de drogas e a violação de direitos em relação. A política repressiva de drogas do Brasil vai contra os fundamentos do Estado Democrático de Direito, pois, busca exterminar o consumo e a comercialização das drogas por meio de uma guerra e afasta-se dos problemas sociais e políticos, dos valores democráticos e constitucionais, das liberdades individuais e do bem estar da população, bem como, rechaça os princípios, ações e projetos da política de redução de danos, que perdem sua eficácia diante da nociva guerra contra as drogas.

Para Ferrajoli (2002) ao se punir o consumo, se acaba na punição da toxicodependência e do usuário ou dependente de drogas, unicamente em virtude de sua condição em relação ao uso de drogas, isto é, ocorre a punição de uma trágica e infeliz condição pessoal de uso ou dependência e de sofrimento que exclui em grande parte, nos casos extremos, a própria vontade da pessoa, contradizendo princípios clássicos do Estado de Direito.

Segundo o autor, qualquer ser humano só pode ser punido apenas pelo que se fez e não pelo que se é ou, pela forma como se age e não pela própria identidade do cidadão. Ensina Ferrajoli (2002) que as proibições incapazes de surtir um mínimo efeito intimidatório na sociedade como a proibição uso de drogas são inofensivas e ineficazes.

A lei de drogas do Brasil, ao caminhar pelo viés repressivo, contraria direitos e garantias constitucionais utilizados na Teoria Garantista de Ferrajoli, como o direito à liberdade, à inviolabilidade da vida privada, à autonomia de escolhas, à lesividade e à proporcionalidade, o que afasta do poder judiciário a adoção da Teoria, que busca assegurar as garantias formais aos indivíduos que se encontrem processados ou condenados contra o poder arbitrário do Estado. 
Segundo Karam (2013), a proibição do consumo de drogas no Brasil, após a década de 1940 é baseada na política de exterminar do país o consumo de drogas, bem como, acabar com as consequências causadas pelo proibicionismo. Porém, após 70 anos de proibição, o alvo da política de drogas não foi conquistado. As drogas estão cada vez mais acessíveis à sociedade, o consumo destas substâncias é elevadíssimo e o tráfico de drogas surge como o maior mercado ilegal, para suprir a vontade e a necessidade dos consumidores, uma vez que, "onde há demanda, há oferta".

Todavia, o que mais é ignorado é que vivemos em um Estado Democrático de Direito, fundado na Constituição Federal e adotados pelo Código Penal, que determina um rol de direitos fundamentais que são indispensáveis à vida digna do ser humano, como por exemplo, o direito à liberdade individual, à intimidade, à vida privada, à igualdade e a apreciação jurisdicional da lesividade, à autonomia e à proporcionalidade, os quais são violados pela criminalização das condutas descritas na atual de drogas.

Assim, ao analisar tais direitos constitucionais e penais notamos que é garantido a todos os indivíduos o direito de gerir a própria vida como desejar, desde que não prejudiquem o outro, cabendo à lei proibir tão somente as ações relevantemente lesivas à sociedade, como não ocorre na maioria dos casos de consumo de drogas, uma vez que o único prejudicado é o próprio consumidor.

Nesse caminho podemos observar que as leis proibitivas do consumo de drogas, além de retrógradas e ineficazes, são também inconstitucionais, da mesma forma que é inconstitucional a aplicação de penalidades ao usuário de drogas que não coloca em risco bens jurídicos relevantes de terceiros, o que já está sendo reconhecido pelo Supremo Tribunal Federal no julgamento do Recurso Extraordinário n. 635.659, que trata da inconstitucionalidade da criminalização do porte de drogas para consumo.

Assim, com base nos princípios garantistas positivados em nossa Constituição Federal analisamos a criminalização das drogas e por consequência do usuário de drogas, uma vez que nenhum sistema penal pode atacar a liberdade individual e valer-se da arbitrariedade do poder para decidir sobre o que os cidadãos podem ou não fazerem, ou quais substâncias devam ou não ser consumidas. 
O Estado não pode substituir o cidadão em suas decisões. O cidadão tem a autonomia constitucional para decidir sobre consumir determinado tipo de droga, desde que a sua conduta não cause prejuízos a terceiros ou não coloque em risco bens jurídicos relevantes, pois, conforme já mencionado, o consumo de drogas é uma conduta de menor potencial ofensivo, um crime de perigo abstrato, e ainda, a penalidade aplicada ao usuário é desproporcional à conduta do consumo de drogas. Assim, se determinada conduta não oferece risco real ou perigo concreto de dano, não deverá ser criminalizada.

\section{BIBLIOGRAFIA}

ACSELRAD, G. org. A educação para a autonomia: construindo um discurso democrático sobre as drogas. In: Avessos do prazer: drogas, Aids e direitos humanos [online]. 2.ed. Rio de Janeiro: Editora FIOCRUZ, 2005, pp. 183-212. Disponível em: http://books.scielo.org/id/bgqvf/epub/acselrad-9788575415368.epub

AGÊNCIA NACIONAL DE VIGILÂNCIA SANITÁRIA - ANVISA. Portaria n. ${ }^{\circ}$ 344, de 12 de maio de 1998, Aprova o Regulamento Técnico sobre substâncias e medicamentos sujeitos a controle especial, 1998.

BIANCHINI. A., MOLINA. A.G., GOMES. L.F., Direito Penal: introdução e princípios fundamentais - 2 ${ }^{\mathrm{a}}$ ed. Ver. E ampliada- São Paulo: Editora Revista dos Tribunais, 2009.

BITTENCOURT, Cezar Roberto. Manual de Direito Penal, 6.ed., São Paulo: Saraiva, 2000.

BRASIL. Constituição Federal de 1988. Constituição da República Federativa do Brasil. São Paulo: Revista dos Tribunais, 2002.

Lei no 11.343/2006, de 23 de agosto de 2006. Institui o Sistema Nacional de Políticas Públicas sobre Drogas - Sisnad; prescreve medidas para prevenção do uso indevido, atenção e reinserção social de usuários e dependentes de drogas; estabelece normas para repressão à produção não autorizada e ao tráfico ilícito de drogas; define crimes e dá outras providências. Brasília, 23 de agosto de 2006.

CARVALHO, Salo de. A Política Criminal de Drogas no Brasil (do discurso oficial às razões da descriminalização. 1996. 365 f. Dissertação (Mestrado) - Programa de Pós-Graduação em Direito. Universidade Federal de Santa Catarina, Florianópolis, 1996.

A política de drogas no Brasil - Estudo criminológico e dogmático da lei 11.343/06. 6. ed., São Paulo: Saraiva, 2013. 
CONSELHO FEDERAL DE PSICOLOGIA. Governo Federal decreta fim da política de Redução de Danos, 2019. Disponível em: https://site.cfp.org.br/governo-federal-decreta-fimda-politica-de-reducao-de-danos/. Acesso em 20 de abril de 2019.

FERRAJOLI, Luigi. Direito e razão: teoria do garantismo penal. São Paulo: Revista dos Tribunais, 2002

. Proibizionismo e diritto. In: Legalizzare la droga: una ragionevole proposta di sperimentazione. Milano: Feltrinelli, 1991.

. Per un Programma de Diritto Penale Minimo, Milano: Feltrinelli, 1983.

FOUCAULT, Michel. Vigiar e Punir: nascimento da prisão. Tradução de Lígia M. Ponde Vassalo. Petrópolis: Vozes, 1987.

GOMES, Luiz Flávio. Drogas e princípio da insignificância: atipicidade material do fato. Jus Navigandi, Teresina, ano 10, n. 1155, 30 ago. 2006. Disponível em Disponível em http://www.lfg.com.br. Acesso em: 12.jan.2019.

HART, Carl. Drogas e sociedade. Disponível em: https://drauziovarella.uol.com.br/drogaslicitas-e-ilicitas/carl-hart-drogas-e-sociedade/. Acesso em 04 de abril de 2019.

KARAM, Maria Lucia. 2009. Escritos sobre a Liberdade, vol.3: Proibições, riscos, danos e enganos: as drogas tornadas ilícitas. Rio de Janeiro: Editora Lumen Juris.

Guerra às drogas encarcera mais negros do que apartheid. Brasil de Fato, São Paulo, 10 dez. 2010. Disponível em: <www.brasildefato.com.br>. Acesso em: 25 ago. 2018.

KELSEN, Hans. Teoria Pura do Direito. $8^{\circ}$ ed., São Paulo: Martins Fontes, 2009.

ROBERTI, Maura. Intervenção Mínima Como Princípio do Direito Penal. São Paulo: Safe, 2007.

ROLIM, Marcos. A síndrome da rainha vermelha: policiamento e segurança pública no Século XXI. 2 ed. Rio de Janeiro: Jorge Zahar Ed: Oxford, Inglaterra: University of Oxford, Centre for Brazilian Studies, 2009.

STRECK, Lênio Luis. O "Crime de Porte de Arma" à Luz da Principiologia Constitucional e do Controle de Constitucionalidade: Três Soluções à Luz da Hermenêutica. Revista de Estudos Criminais do ITEC, p. 54, 2001, Disponível em: http://www.mpsp.mp.br/portal/page/portal/documentacao_e_divulgacao/doc_biblioteca/bibli_ servicos_produtos/bibli_boletim/bibli_bol_2006/SRC\%2001_52.pdf. Acesso em 19.jan. 2019.

SUPREMO TRIBUNAL FEDERAL. Recurso Extraordinário n. 635.659-RG. Disponível em: https://www.migalhas.com.br/arquivos/2015/9/art20150910-12.pdf. Acesso em 05 de abril de 2019. 
TRIBUNAL DE JUSTIÇA DO RIO GRANDE DO SUL. Apelação Criminal n. 687043661, voto vencido do desembargador Milton dos Santos Martins. Disponível em: www.mpsp.mp.br/portal/page/portal/Assessoria_Juridica/Controle_Constitucionalidade.

Acesso em: 26. jan.2019.

Submetido em: 17/05/2019

Aceito em: 23/09/2019 